\title{
Neuroimaging research in human MDMA users: a review
}

\author{
Ronald L. Cowan
}

Received: 2 June 2005 / Accepted: 1 June 2006 / Published online: 18 July 2006

(C) Springer-Verlag 2006

\begin{abstract}
Rationale Determining whether, under what circumstances, and to what extent 3,4-methylenedioxymethamphetamine (MDMA) exposure produces chronic changes in human brain function is a critical public health issue. MDMA is a widely used recreational drug commonly sold as "Ecstasy". Because findings from the animal literature have indicated that specific dosage regimens of MDMA can produce longlasting alterations in serotonergic function, existing studies of MDMA effects in humans have examined brain serotonin (5-HT) transporters (5-HTT) and receptors or have examined brain structures or functions potentially affected by MDMA. Objectives The objectives of this review are to provide a background for interpreting human MDMA neuroimaging research, to examine existing neuroimaging data regarding the rationale for and limitations to human MDMA research, and to provide suggestions for improving the design and interpretation of future neuroimaging approaches.

Results Of the existing neuroimaging studies in human MDMA users, few experimental designs have been replicated across different research groups. Only investigations employing nuclear imaging methods to assay brain 5-HTT levels have been replicated across methods and research laboratories. These studies have found reduced levels of the 5-HTT in recently abstinent MDMA users with some evidence for normalization of 5-HTT levels with prolonged abstinence. However, the sensitivity of these methods is unknown.
\end{abstract}

R. L. Cowan $(\bowtie)$

Psychiatric Neuroimaging Program, Department of Psychiatry,

Vanderbilt University Medical Center,

1500 21st Avenue South, Suite 3000,

Nashville, TN 37212, USA

e-mail: Ronald.L.Cowan@Vanderbilt.edu
Conclusions The current state of neuroimaging in human MDMA users does not permit conclusions regarding the long-term effects of MDMA exposure. Future study designs might benefit from improved sample homogeneity, increased length of MDMA abstinence, longitudinal study design, test-retest measures, serotonergic specificity, and multimodal approaches.

Keywords 3,4-Methylenedioxymethamphetamine. MDMA $\cdot$ Ecstasy $\cdot$ Neuroimaging $\cdot$ Drug abuse .

Drug toxicity $\cdot$ PET $\cdot$ SPECT $\cdot$ fMRI

\section{Introduction}

Determining whether, under what circumstances, and to what extent 3,4-methylenedioxymethamphetamine (MDMA) exposure produces chronic changes in human brain function is a critical public health issue. While the name MDMA is often used as synonymous with Ecstasy in much of the world's published literature, it should be noted that numerous preparations may be sold as MDMA or as Ecstasy but do not necessarily contain MDMA (Cole et al. 2002; Parrott 2004; Tanner-Smith 2006). For clarity, this manuscript will refer to Ecstasy users as MDMA users, but it is important to emphasize that pure MDMA is administered in research studies while Ecstasy, potentially containing only MDMA or no MDMA, is ingested by human subjects intent on using MDMA. Recreational users of MDMA, researchers, and the press have challenged the utility and validity of studies from the animal literature while anecdotal and empirical evidence suggests that public health messages regarding MDMA toxicity continue to be met with some skepticism (ABC Television Network 2004; Check 2004; Green 2004; The Partnership for a Drug-Free 
America 2003; National Drug Intelligence Center 2005). While MDMA use in the United States appears to have peaked in 2001 (National Drug Intelligence Center 2005; The Partnership for a Drug-Free America 2003), rates of MDMA use in the European Union continue to increase (European Monitoring Centre for Drugs and Drug Addiction 2005). Furthermore, consideration of MDMA's therapeutic potential is gaining increasing acceptance from the United States Food and Drug Administration (FDA) as witnessed by current clinical trials exploring MDMA's efficacy in the treatment of refractory posttraumatic stress disorder and cancer-associated anxiety (Newton 2001; Doblin 2002; Kohn 2004; Crittenden 2005; Marsa 2005).

Animal studies suggesting that MDMA administration may produce long-lasting or even permanent brain changes have fueled research efforts to better understand the relationship between animal administration research and brain consequences in human MDMA users (for review, see Green et al. 2003; Lyles and Cadet 2003; Morton 2005). Although the extensive animal literature on MDMA effects cannot be reviewed in detail in this manuscript, numerous animal studies have revealed that MDMA (when given in sufficiently large or sufficiently frequent dosages) produces long-term alterations in 5-HT function (reviewed in Green et al. 2003; Lyles and Cadet 2003; Morton 2005) in rodents and nonhuman primates. These changes, including reductions in the levels of 5-HT, the 5-HT synthetic enzyme tryptophan hydroxylase, and the 5-HT reuptake transporter (5-HTT; SERT), have been generally interpreted as indicative of chronic MDMA-induced changes in brain 5-HT function (Kish 2002; Green et al. 2003; Lyles and Cadet 2003). Findings of degenerating axons and 5-HT axon reorganization in some MDMA administration studies in animals have led to the concern that human MDMA users may suffer irreversible loss of ascending serotonergic innervation (Kish 2002; Green et al. 2003; Lyles and Cadet 2003). Further confounding the implication of animal studies for human MDMA users are recent findings in animal models indicating that loss of some 5-HT markers is not necessarily consistent with axon destruction (Fantegrossi et al. 2004; Wang et al. 2004, 2005). In addition, the degree to which MDMA dosages and dosage regimens employed in animal research mirror those used recreationally by humans also remains unclear (Lieberman and Aghajanian 1999; McCann and Ricaurte 2001; de la Torre and Farre 2004; Irvine et al. 2006).

Because basic research findings have associated MDMA exposure with specific long-term effects on 5-HT function, neuroimaging studies in human MDMA users have directly assayed components of the 5-HT system (McCann et al. 1998; Semple et al. 1999; Reneman et al. 2000a,b, 2001a, 2002c; Buchert et al. 2004; de Win et al. 2004; McCann et al. 2005), have assessed brain structure or function poten- tially altered as a secondary consequence of perturbed 5-HT function, or have examined brain regions implicated in MDMA-induced cognitive alterations (Chang et al. 1999, 2000; Obrocki et al. 1999, 2002; Buchert et al. 2001; Gamma et al. 2001; Obergriesser et al. 2001; Reneman et al. 2001d,e, 2002d; Cowan et al. 2003; Daumann et al. 2003a,b, 2004a,b, 2005; Jacobsen et al. 2004; Moeller et al. 2004; reviewed in Morgan 2000; Parrott 2001; Montoya et al. 2002). This review examines currently available findings in the context of putative 5-HT toxicity and/or functional alterations with regard to brain structure and physiology. As such, neuroimaging studies of the acute effects of MDMA are not discussed.

Before discussing current neuroimaging findings in MDMA users, several caveats are in order. First, although this review and existing human neuroimaging studies have focused on serotonergic effects of MDMA exposure, it should be made clear that MDMA is a complex pharmacological agent having a broad range of effects across multiple neurotransmitter systems (e.g., Bankson and Cunningham 2001; Green et al. 2003; Simantov 2004; Verrico et al. 2005; Nair and Gudelsky 2006). Second, the nearly ubiquitous presence of concomitant polydrug use in contemporary MDMA users suggests that much human MDMA research might frequently be better characterized as MDMA-polydrug investigations (e.g., Schifano et al. 1998; Pedersen and Skrondal 1999; Gross et al. 2002; de Almeida and Silva 2003; Scholey et al. 2004). Third, like all research in human recreational drug users, MDMA neuroimaging research based on exposure in a naturalistic setting is subject to variability introduced by many uncontrolled factors (Green 2004). Issues such as potentially preexisting brain differences, sex effects, genetic effects, and environmental factors may influence the actual consequences of exposure to a specific drug and/or the research tools employed to detect such consequences. Given these circumstances, successful neuroimaging investigations in MDMA users face considerable challenges to their design, implementation, and interpretation.

In this murky environment of competing contentions regarding MDMA's therapeutic or neurotoxic effects, its association with polydrug exposure, unknown pill purity, and challenges deriving from research in an uncontrolled setting, it seems timely to review the extant neuroimaging data derived from studies of human MDMA users. Earlier MDMA neuroimaging reviews (Reneman et al. 2001b, 2006; Hurley et al. 2002; Kish 2002) are good resources for a detailed examination of methodological considerations. A recent review of neuroimaging in multiple drugs of abuse offers a brief overview of findings with an emphasis on ischemic effects (Rojas et al. 2005). The present review has three parts: (1) this brief introduction highlighting studies that provide the foundation for human neuroimaging 
investigations, (2) a review of human MDMA neuroimaging research to date, and (3) a summary of the implications of existing studies and suggested future directions for MDMA neuroimaging research.

\section{Neuroimaging}

Neuroimaging explorations in human MDMA users have been rooted in examining the direct or indirect pathology of the 5-HT system or in investigating neural correlates of cognitive processes demonstrated to be impaired in MDMA users.

\section{Imaging the 5-HT system}

Because 5-HT alterations have been the primary focus of much of the basic and clinical literature with regard to MDMA toxicity, it is not surprising that initial neuroimaging efforts have focused on markers of serotonergic integrity. These have included the 5-HTT as a potential marker for axons (Table 1) and $5-\mathrm{HT}_{2 \mathrm{~A}}$ receptors as potential indirect markers reflecting changes in 5-HT synaptic concentrations.

\section{The 5-HT reuptake transporter (5-HTT)}

The 5-HTT is distributed along the entire course of 5-HT axons rather than solely at the synaptic terminal (Zhou et al. 1998; Miner et al. 2000). As a result, loss of serotonergic axons would be predicted to result in reduced levels of the 5HTT in affected regions, providing an intriguing target marker to investigate MDMA-induced axon toxicity. Detection of 5-HT axon loss, using 5-HTT density as a surrogate, is complicated by several factors, including potential variability in 5-HTT expression associated with age (Yamamoto et al. 2002), 5-HTT gene transporter region polymorphisms (e.g., Lesch et al. 1996), and by the fact that 5-HTT levels can be functionally up- or down-regulated in the absence of axon destruction (reviewed in Kish 2002; e.g., Horschitz et al. 2001; Benmansour et al. 2002).

Findings from positron emission tomography (PET) and single photon emission computed tomography (SPECT) imaging have consistently revealed reductions in 5-HTT ligand binding in recently abstinent (roughly those abstinent less than 6 months) MDMA users. SPECT studies in MDMA users (Semple et al. 1999; Reneman et al. 2001a) are generally in agreement with PET findings and due to the lower specificity and sensitivity of the commonly employed SPECT ligand 2beta-carbomethoxy-3beta-(4-[(123)I]iodophenyl)tropane $\left(\left[{ }^{123} \mathrm{I}\right] \beta-\mathrm{CIT}\right)$, SPECT studies of MDMA users will be briefly summarized but will not be detailed in this review. $\left.{ }^{[23} \mathrm{I}\right] \beta$-CIT binds to both the 5-HTT and the dopamine transporter (DAT). Cortical binding of this ligand is considered to largely assay the 5-HTT whereas striatal binding is considered to assay the DAT (For a discussion of the issues involved in using $\left[{ }^{123} \mathrm{I}\right] \beta$-CIT to assay 5-HTT levels, see Kish 2002; Reneman et al. 2002a, 2006). Semple et al. (1999) used $\left[{ }^{123} \mathrm{I}\right] \beta$-CIT to compare cortical 5-HTT binding and subcortical DAT binding in male MDMA users and controls. MDMA users showed reduced 5-HTT density in neocortex with a positive correlation between the duration of MDMA abstinence and $\left[{ }^{123} \mathrm{I}\right] \beta$-CIT binding in cortex. Subcortical $\left[{ }^{123} \mathrm{I}\right] \beta$-CIT binding (reflecting DAT levels) was not different between MDMA users and controls. Reneman and colleagues (Reneman et al. 2001a,c; de Win et al. 2004) published a series of manuscripts using $\left[{ }^{123} \mathrm{I}\right] \beta$-CIT SPECT to investigate 5-HTT levels in a cohort of MDMA users and controls. Examining moderate, heavy, and former MDMA users (abstinent from MDMA at least 1 year), Reneman et al. (2001a) reported decreased 5-HTT in female (but not male) heavy MDMA users whereas 5-HTT levels in female former MDMA users were comparable to controls. When verbal memory was assessed in MDMA users and compared to 5-HTT levels (Reneman et al. 2001c), current and former MDMA users showed impaired verbal memory but there was no detectable relationship between verbal memory performance and 5-HTT density. In a comparison of mood and 5-HTT levels, de Win et al. (2004) found no association between sex, mood, and 5-HTT binding. As assessed using the Composite International Diagnostic Interview [CIDI; a structured clinical interview corresponding to diagnostic criteria of the Diagnostic and Statistical Manual of Mental Disorders, Fourth Edition (DSM-IV: American Psychiatric Association Press 1994)] MDMA users did not show increased lifetime levels of clinical depression compared to polydrug controls. When examined using the Beck Depression Inventory (BDI), former MDMA users showed higher current depression scale scores than the non-MDMA exposed controls. An additional manuscript (Reneman et al. 2002b) used $\left[{ }^{123} \mathrm{I}\right] \beta$-CIT to assay striatal DAT binding in a cohort of MDMA naïve controls, MDMA users, and combined MDMA/amphetamine users. This preliminary investigation found higher $\left[{ }^{123} \mathrm{I}\right] \beta$-CIT binding in the striatum of MDMA users relative to controls, whereas combined MDMA/amphetamine users showed reduced $\left[{ }^{123} \mathrm{I}\right] \beta$-CIT binding relative to the comparison group - the latter finding consistent with reductions in the levels of the DAT.

McCann et al. (1998) used the PET ligand $\left[{ }^{11} \mathrm{C}\right] \mathrm{McN}$ 5652 to assay 5-HTT levels in MDMA users and healthy controls. MDMA users had used MDMA an average of 228 times (range 70 to 400 times) and reported abstinence from the drug for a minimum of 3 weeks (mean abstinence period of 19 weeks; range 3-147 weeks). Serum and urine drug screens were used to verify abstinence from all drugs of 
Table 1 5-HTT neuroimaging in MDMA users

\begin{tabular}{|c|c|c|c|c|c|c|c|}
\hline Ligand & Result & Method & $\begin{array}{l}\text { MDMA use } \\
\text { mean (SD) }\end{array}$ & $\begin{array}{l}\text { MDMA } \\
\text { abstinence } \\
\text { mean (SD) }\end{array}$ & Sample size & Comment & Reference \\
\hline $\begin{array}{l}{\left[{ }^{123} \mathrm{I}\right]} \\
\beta-\mathrm{CIT}\end{array}$ & $\begin{array}{l}\text { Lower 5-HTT } \\
\text { levels in } \\
\text { posterior } \\
\text { cortex in } \\
\text { MDMA users }\end{array}$ & SPECT & $\begin{array}{l}672(647) \\
\text { tablets }\end{array}$ & 18 (8.0) days & $\begin{array}{l}10 \text { MDMA; } \\
10 \text { control }\end{array}$ & $\begin{array}{l}\text { Hair sampling } \\
\text { used to assess } \\
\text { MDMA } \\
\text { exposure; } \\
\text { no specified } \\
\text { drug abstinent } \\
\text { period }\end{array}$ & $\begin{array}{l}\text { Semple } \\
\text { et al. } 1999\end{array}$ \\
\hline $\begin{array}{l}{\left[{ }^{123} \mathrm{I}\right]} \\
\beta-\mathrm{CIT}\end{array}$ & $\begin{array}{l}\text { Normal 5-HTT } \\
\text { levels in moderate } \\
\text { MDMA users; } \\
\text { lower 5-HTT levels } \\
\text { in female (but not } \\
\text { male) heavy } \\
\text { MDMA users; } \\
\text { normal 5-HTT } \\
\text { levels in former } \\
\text { MDMA users }\end{array}$ & SPECT & $\begin{array}{l}28.6(17.8) \text { tablets } \\
\text { (moderate } \\
\text { MDMA } \\
\text { users); 530.0 } \\
\text { (621.1) tablets } \\
\text { (heavy MDMA } \\
\text { users); 268.1 } \\
\text { (614.3) tablets } \\
\text { (former MDMA } \\
\text { users) }\end{array}$ & $\begin{array}{l}109.5 \text { (179.5) } \\
\text { days (moderate } \\
\text { MDMA users); } \\
69.9 \text { (73.0) } \\
\text { days (heavy } \\
\text { MDMA users); } \\
\text { 882.2 (620.57) } \\
\text { days (former } \\
\text { MDMA users) }\end{array}$ & $\begin{array}{l}15 \text { moderate } \\
\text { MDMA; } 23 \\
\text { heavy MDMA; } \\
16 \text { ex-MDMA; } \\
15 \text { control }\end{array}$ & & $\begin{array}{l}\text { Reneman et } \\
\text { al. 2001a } \\
\text { (Reneman } \\
\text { et al. 2001c; } \\
\text { de Win et } \\
\text { al. 2004) }\end{array}$ \\
\hline $\begin{array}{l}{\left[{ }^{11} \mathrm{C}\right]} \\
\mathrm{McN} 5652\end{array}$ & $\begin{array}{l}\text { Lower 5-HTT } \\
\text { ligand binding } \\
\text { in MDMA } \\
\text { users in multiple } \\
\text { brain regions }\end{array}$ & PET & $\begin{array}{l}228^{\mathrm{b}}(\text { n.g. }) \\
\text { exposures }\end{array}$ & 133 days (n.g.) & $\begin{array}{l}14 \text { former } \\
\text { MDMA; } \\
15 \text { control }\end{array}$ & & $\begin{array}{l}\text { McCann } \\
\text { et al. } 1998 \\
\text { (Ricaurte } \\
\text { et al. 2000) }\end{array}$ \\
\hline $\begin{array}{l}{\left[{ }^{11} \mathrm{C}\right]} \\
\mathrm{McN} 5652\end{array}$ & $\begin{array}{l}\text { Lower 5-HTT } \\
\text { ligand binding in } \\
\text { current MDMA } \\
\text { users in multiple } \\
\text { brain regions; } \\
\text { normal 5-HTT } \\
\text { ligand binding } \\
\text { in former } \\
\text { MDMA users }\end{array}$ & PET & $\begin{array}{l}831(1,269) \\
\text { tablets (current } \\
\text { MDMA users); } \\
793 \text { (677) tablets } \\
\text { (former MDMA } \\
\text { users) }\end{array}$ & $\begin{array}{l}25 \text { (15) days } \\
\text { (current MDMA } \\
\text { users); } 520 \text { (486) } \\
\text { days (former } \\
\text { MDMA users) }\end{array}$ & $\begin{array}{l}30 \text { current } \\
\text { MDMA; } 29 \\
\text { drug naïve; } 29 \\
\text { non-MDMA } \\
\text { polydrug; } 29 \\
\text { former MDMA }\end{array}$ & $\begin{array}{l}\text { Hair sampling } \\
\text { used to assess } \\
\text { MDMA } \\
\text { exposure; } \\
3 \text { days } \\
\text { abstinence } \\
\text { all drugs }\end{array}$ & $\begin{array}{l}\text { Buchert et } \\
\text { al. 2004 } \\
\text { (Buchert } \\
\text { et al. 2003; } \\
\text { Thomasius } \\
\text { et al. 2003) }\end{array}$ \\
\hline $\begin{array}{l}{\left[{ }^{11} \mathrm{C}\right]} \\
\mathrm{McN} 5652 \\
\text { and }\left[{ }^{11} \mathrm{C}\right] \\
\text { DASB }\end{array}$ & $\begin{array}{l}\text { Lower 5-HTT } \\
\text { ligand binding } \\
\text { in MDMA } \\
\text { users in multiple } \\
\text { brain regions }\end{array}$ & PET & $\begin{array}{l}96.96^{\mathrm{c}} \text { (n.g.) } \\
\text { exposures }\end{array}$ & $\begin{array}{l}144.2(264.8) \\
\text { days }\end{array}$ & $\begin{array}{c}23 \text { MDMA; } \\
19 \text { control }\end{array}$ & $\begin{array}{l}2 \text { weeks } \\
\text { abstinence } \\
\text { all drugs }\end{array}$ & $\begin{array}{l}\text { McCann } \\
\text { et al. } 2005\end{array}$ \\
\hline
\end{tabular}

n.g. Not given

${ }^{a}$ Main results presented in Reneman et al. 2001a

${ }^{b}$ Mean number of tablets not given. SD not given for exposures, range for exposures was (28-324)

${ }^{\mathrm{c}}$ Mean number of tablets not given. SD not given for exposures, range for exposures was $(70-400)$

abuse. MDMA users had globally and regionally reduced $\left[{ }^{11} \mathrm{C}\right] \mathrm{McN}-5652$ binding that did not correlate with duration of MDMA abstinence but that was inversely correlated with the degree of prior MDMA exposure, suggesting the possibility of dose-related MDMA toxicity. The findings from this report (McCann et al. 1998) were represented in parallel with validation studies of the method in baboons in Ricaurte et al. (2000). As critiqued by Kish (2002) and discussed in McCann et al. (2005), the McCann et al. (1998) study used methodological approaches that theoretically limited the strength of findings from this study. However, as discussed below, these results have now been largely replicated by other investigators (Buchert et al. 2004) using (11)C-(+)-6beta-(4-methylthiophenyl)-1,2,3,5,6 alpha, 10beta-hexahydropyrrolo[2,1-a]isoquinoline ([ $\left.{ }^{11} \mathrm{C}\right] \mathrm{McN}-$ 5652) and by McCann et al. (2005) using an additional 5-HTT PET ligand (11)C-3-amino-4-(2-dimethylaminomethylphenylthio)benzonitrile $\left(\left[{ }^{11} \mathrm{C}\right] \mathrm{DASB}\right)$ (Frankle et al. 2004).

After the McCann et al. (1998) report, a series of reports (Buchert et al. 2003, 2004; Thomasius et al. 2003) used $\left[{ }^{11} \mathrm{C}\right] \mathrm{McN}-5652$ PET to examine 5-HTT status in MDMA 
users and controls. As the different manuscripts highlight slightly different aspects of the overall group, only the data from the Buchert et al. (2004) manuscript will be considered in detail. Buchert et al. (2004) examined 5-HTT binding in controls, MDMA-naïve polydrug users (illicit drug use but never used MDMA), current MDMA users, and former MDMA users [abstinent 20 weeks or longer and having used at least 250 MDMA tablets (females) or at least 400 MDMA tablets (males) (Buchert et al. 2004)]. Males and females were roughly balanced in each group, with a total of 59 males and 58 females participating. Similar to the initial report of McCann et al. (1998), Buchert and colleagues found significant reductions in 5-HTT ligand binding in cortical and subcortical regions of current MDMA users relative to all three comparison groups. Female MDMA users had greater overall reductions in 5-HTT ligand binding than male users. The former MDMA users had a mean abstinent period of 520 days with a range of 29-1,500 days, with comparable prior MDMA exposure to that of the current MDMA users. For all MDMA users, there was a positive correlation between duration of MDMA-abstinence and 5-HTT ligand binding in basal forebrain and brainstem regions. The fact that longabstinent MDMA users showed no differences in 5-HTT ligand binding when compared to the two control groups led Buchert et al. (2004) to suggest that MDMA-associated decrements in 5-HTT binding are potentially reversible. The relationship between neuropsychiatric tests and 5-HTT status in this cohort of users was reported in Thomasius et al. (2003). This report included a detailed survey of polydrug use parameters and MDMA use patterns. While all drug-using groups (i.e., MDMA-naïve polydrug, current MDMA, and former MDMA) showed increased psychopathology relative to the control group, the former MDMA user group showed impaired memory recall in the verbal domain. Only current MDMA users had evidence for reduced 5-HTT levels in the tested regions.

McCann et al. (2005) recently replicated and extended the results of their earlier study (McCann et al. 1998) utilizing both $\left[{ }^{11} \mathrm{C}\right] \mathrm{McN}-5652$ and a more recently developed PET 5-HTT ligand $\left[{ }^{11} \mathrm{C}\right]$ DASB, the latter ligand offering potentially increased specificity for 5-HTT level assessment compared to $\left[{ }^{11} \mathrm{C}\right] \mathrm{McN}-5652$ (Frankle et al. 2004). MDMA users $(n=23)$ in this study had on average 96.96 episodes of MDMA use with a range of 28-324 exposures while control subjects $(n=19)$ reported no prior MDMA use. The mean abstinence period from MDMA use was $144 \pm 265$ days. All subjects reported drug abstinence for at least 2 weeks before the study and urine drug screens were negative at study enrollment (except that marijuana positive drug screens were permitted). Using multiple methods for assessing 5-HTT levels and a side by side comparison of the two ligands, McCann and colleagues again found global and regional reductions in 5-HTT binding in MDMA users across ligands and methods (with somewhat superior performance of $\left.\left[{ }^{11} \mathrm{C}\right] \mathrm{DASB}\right)$. Brain regions having significantly reduced ligand binding included the amygdala, hippocampus, thalamus, and cortical regions (frontal, occipital, orbitofrontal, parietal, anterior, and posterior cingulate). Exploratory analyses revealed an inverse association between the typical monthly dose of MDMA exposure and 5-HTT ligand binding, as well as evidence for regional and global recovery of 5-HTT ligand binding with increased abstinence from MDMA. However, these authors pointed out that the sensitivity of PET ligand binding for detecting reduced 5-HTT is unknown.

Summary In summary, nuclear imaging studies using various methodologies and multiple ligands have demonstrated that MDMA users have reduced brain 5-HTT levels. In addition, these studies have generally revealed an association between the degree of MDMA exposure and the degree of reduction in 5-HTT ligand binding, with evidence for 5-HTT recovery with increased duration of MDMA abstinence. The sensitivity of nuclear imaging methods to detect reductions in 5-HTT levels requires further clarification.

\section{5- $\mathrm{HT}_{2 A}$ receptors}

In addition to the 5-HTT, $5-\mathrm{HT}_{2 \mathrm{~A}}$ receptors are important components of the serotonergic system and can be assayed in humans. 5- $\mathrm{HT}_{2 \mathrm{~A}}$ receptors have a widespread distribution in the central nervous system (CNS) with dense binding in human neocortex but lower concentrations subcortically (e.g., Varnas et al. 2004). Given their postsynaptic location, $5-\mathrm{HT}_{2 \mathrm{~A}}$ receptors are positioned to indirectly reflect synaptic 5 -HT release and can potentially serve as a complementary measure to 5-HTT levels in determining whether MDMA has long-term functional consequences in human users (Scheffel et al. 1992; Reneman et al. 2000a,b, 2002c). The utility of 5- $\mathrm{HT}_{2 \mathrm{~A}}$ receptor levels in understanding MDMA's chronic effects is limited by current uncertainties regarding the expected response of $5-\mathrm{HT}_{2 \mathrm{~A}}$ receptor levels to events such as serotonergic axotomy or chronic down-regulation of the 5-HTT. The 5-HT $2 \mathrm{~A}$ receptor largely displays activity classically associated with G-protein coupled receptors and down-regulates with sustained exposure to agonists and upregulates in the absence of agonist (reviewed in Gray and Roth 2001; Van Oekelen et al. 2003). The response of the $5-\mathrm{HT}_{2 \mathrm{~A}}$ receptor to antagonist exposure is less predictable and is frequently paradoxical (e.g., Fiorella et al. 1995; Gray and Roth 2001; Van Oekelen et al. 2003). MDMA administration in rodents has produced variable results with regard to $5-\mathrm{HT}_{2}$ receptor assays $\left(5-\mathrm{HT}_{2}\right.$ binding in neocortex 
is considered largely reflective of $5-\mathrm{HT}_{2 \mathrm{~A}}$ receptor status). For example, Scheffel et al. (1992) and Reneman et al. (2002c) reported decreased 5- $\mathrm{HT}_{2}$ receptor levels in rats in the acute phase after MDMA exposure. When assayed at 21 days in the Scheffel et al. (1992) report, receptor binding had normalized, whereas in the Reneman et al. (2002c) study, $5-\mathrm{HT}_{2 \mathrm{~A}}$ receptor levels were increased in frontal cortex when examined at 30 days. Reneman and colleagues interpreted these findings as consistent with 5-HT-induced subchronic receptor downregulation followed by a denervation (5-HT-depletion)-induced compensatory receptor up regulation. In contrast, and using different methods, MDMA-exposed rats assayed 3-months postexposure showed clear reductions in cortical, thalamic, and hypothalamic $5-\mathrm{HT}_{2}\left(5-\mathrm{HT}_{2 \mathrm{~A} / 2 \mathrm{C}}\right)$ receptor density as visualized using $\left[{ }^{125} \mathrm{I}\right]$ 1-(2,5-dimethoxy-4-iodophenyl)-2-aminopropane (DOI) quantitative autoradiography (McGregor et al. 2003). These diverging findings may be the result of different MDMA administration paradigms (e.g., route, dosage, and frequency) and other methodological variations (e.g., ligand specificity) but illustrate the complexity of developing an animal model for interpreting results in human MDMA users. Sex (Moses-Kolko et al. 2003) and genotypic (e.g., Turecki et al. 1999) variations in receptor expression also potentially add to experimental variability.

Three studies of 5- $\mathrm{HT}_{2 \mathrm{~A}}$ receptors in human MDMA users have been published by Reneman and colleagues (Reneman et al. 2000a,b, 2002c). In an initial report employing $\left[{ }^{123} \mathrm{I}\right] \mathrm{R} 91150$ SPECT (a specific, reversible ligand of the $5-\mathrm{HT}_{2 \mathrm{~A}}$ receptor), Reneman et al. (2000a) compared cortical $5-\mathrm{HT}_{2 \mathrm{~A}}$ receptor levels and verbal memory in a small group of MDMA users $(n=5)$ vs nine drug-naïve controls (matched for age and education level). MDMA users had used a minimum of 50 MDMA tablets (mean use 218 tablets) and reported a minimum abstinence period from all drugs of 2 months (mean time from last MDMA usage was 4.6 months). Details of polydrug exposure in the MDMA cohort were not provided, but MDMA users primarily reported prior use of alcohol and cannabis. Urine drug screens were negative for all subjects at study enrollment. With regard to $5-\mathrm{HT}_{2 \mathrm{~A}}$ receptor levels, overall binding was not different between MDMA users and controls. When ligand binding was assessed by brain region (frontal, parietal, temporal, and occipital cortex), MDMA users had significantly increased expression of $5-\mathrm{HT}_{2 \mathrm{~A}}$ receptors in occipital cortex. MDMA users showed significantly reduced word recall when compared to the control group. There was no correlation between $5-\mathrm{HT}_{2 \mathrm{~A}}$ binding and word recall in controls, but within the MDMA users, increased overall receptor levels (i.e., all cortical regions included) was strongly correlated with impaired word recall memory performance, hinting at a functional consequence of altered 5-HT transmission.
In a subsequent study employing $\left[{ }^{123} \mathrm{I}\right] \mathrm{R} 91150$ SPECT and methods similar to the initial study (Reneman et al. 2000a), Reneman et al. (2000b) examined 5- $\mathrm{HT}_{2 \mathrm{~A}}$ receptor binding and regional cerebral blood volume (rCBV) in three groups: controls ( $n=10$; no prior MDMA use), recent MDMA users $(n=10$; subjects having a mean abstinence period of 7 weeks), and abstinent MDMA users $(n=5$; subjects having a mean abstinence period of 18 weeks). The intent of this study was to determine whether $5-\mathrm{HT}_{2 \mathrm{~A}}$ receptor levels suggested an influence of MDMA on vascular diameter as assayed by $\mathrm{rCBV}[\mathrm{rCBV}$ was measured in a small subset of subjects using the magnetic resonance imaging (MRI) dynamic susceptibility contrast method]. Given that 5-HT innervates cerebral microvessels (having a mixed, but mainly vasoconstrictive effect) altered 5-HT innervation to cerebral blood vessels might produce changes in resting vascular tone (Cohen et al. 1996). The investigators hypothesized that low levels of $5-\mathrm{HT}_{2 \mathrm{~A}}$ receptors would correlate with vasoconstriction and decreased rCBV (consistent with increased presynaptic 5-HT signaling), whereas high levels of $5-\mathrm{HT}_{2 \mathrm{~A}}$ receptors would correlate with vasodilation and increased rCBV (consistent with reduced presynaptic 5-HT signaling). As predicted, the analysis of $5-\mathrm{HT}_{2 \mathrm{~A}}$ receptor binding found reduced $5-\mathrm{HT}_{2 \mathrm{~A}}$ receptor levels in recent MDMA users vs controls and ex-MDMA users, consistent with acute receptor down-regulation by ongoing 5-HT release. The subset of participants who underwent rCBV assessment included three recent MDMA users, two ex-MDMA users, and six controls. While there were no significant differences in $\mathrm{rCBV}$ between the five MDMA users and six controls, the $\mathrm{rCBV}$ in two brain regions (the globus pallidus and occipital cortex) was positively correlated with $5-\mathrm{HT}_{2 \mathrm{~A}}$ receptor binding in the MDMA users but not the control subjects.

The final study by Reneman et al. (2002c) combined data from the Reneman et al. 2000a and b reports and also conducted a similar analysis in rats. In the aggregate data analysis, $5-\mathrm{HT}_{2 \mathrm{~A}}$ receptor binding was reduced in recent MDMA users in the three cortical regions assayed (frontal, parietal, and occipital cortex) when compared to controls. In the former MDMA users, $5-\mathrm{HT}_{2 \mathrm{~A}}$ receptor binding was significantly greater than controls only for occipital regions (Reneman et al. 2002c).

Summary To date, published studies of $5-\mathrm{HT}_{2 \mathrm{~A}}$ receptor levels in human MDMA users have been limited to a single research group. At present, the referenced studies of $5-\mathrm{HT}_{2 \mathrm{~A}}$ binding in human MDMA users appear consistent with classically expected G-protein coupled receptor activity of the 5- $\mathrm{HT}_{2 \mathrm{~A}}$ receptor with indirect evidence for reduced receptor binding during active MDMA use but with increased receptor binding in longer-abstinent subjects-a 
finding potentially consistent with long-lasting reductions in 5-HT release and compensatory receptor up-regulation. There is early evidence from a small sample size to suggest that altered $5-\mathrm{HT}_{2 \mathrm{~A}}$ receptor levels correlate with $\mathrm{rCBV}$.

Neuroimaging blood flow and volume, brain volume, and brain metabolites

\section{Blood flow and blood volume}

As described above (Reneman et al. 2000b) MDMA exposure might chronically alter resting cerebral blood flow or blood volume via mechanisms including direct alteration of serotonergic microvascular innervation. MDMA-induced changes in neuronal volume or functional integrity might also occur due to chronic neuronal loss due to acute ischemic effects of MDMA (Reneman et al. 2001e) and/or altered 5-HT-linked trophic factor release (Cowan et al. 2003).

Using 133-xenon SPECT, Chang et al. (2000) examined the effects of prior MDMA exposure on regional cerebral blood flow (rCBF) in drug-abstinent MDMA users at baseline and again after administration of MDMA. The study enrolled 21 drug-naïve controls and 21 "low dose" MDMA users - namely, those who had used less than $3 \mathrm{mg} / \mathrm{kg}$ per use and those who used six or more times per year for at least 1 year. MDMA users reported a mean of $211 \pm 340$ episodes of MDMA use with a mean abstinence period of $6.6 \pm 7.7$ months. The average lifetime MDMA use was $13.1 \mathrm{~g}$. Subjects reported use of multiple recreational drugs, but denied use of drugs other than MDMA within 6 months of the study. Study-day urine drug screens were negative for all subjects. With regard to the chronic effects of MDMA exposure in abstinent MDMA users, Chang and colleagues found no significant differences in global and rCBF between MDMA users and controls. A subgroup of 10 subjects was given oral dosages of MDMA on two occasions. The second dosage of MDMA was administered 1 week to 21 days after the initial dose. The total MDMA dosage ranged from $2.25-4.75 \mathrm{mg} / \mathrm{kg}$. Subjects who were restudied 2 to 3 weeks post-MDMA administration showed significant $\mathrm{rCBF}$ reductions in multiple brain regions including bilateral caudate, bilateral superior parietal cortex, and right dorsolateral prefrontal cortex. These latter findings suggested a subchronic persistent vasoconstrictive effect of MDMA administration, leading Chang et al. (2000) to speculate that long-lasting MDMA metabolites or other changes in serotonergic function might underlie the observed findings.

As reviewed above in the context of the relationship between $5-\mathrm{HT}_{2 \mathrm{~A}}$ receptors and $\mathrm{rCBV}$, an initial investigation (Reneman et al. 2000b) found no significant differences in rCBV between a small group of MDMA users and controls, but the rCBV in the globus pallidus and occipital cortex was positively correlated with $5-\mathrm{HT}_{2 \mathrm{~A}}$ receptor binding in the MDMA users. A subsequent investigation (Reneman et al. 2001e) assessed frontal and occipital cortical and lentiform nucleus (consisting of the putamen and globus pallidus) rCBV in a group of MDMA users abstinent at least 3 weeks from MDMA and other drugs. MDMA users did not show significant differences compared to controls in frontal or occipital cortical areas. With regard to the lentiform nucleus, rCBV in the putamen did not differ between MDMA users and controls. However, rCBV was significantly greater in the globus pallidi of MDMA users. These authors interpreted the increased $\mathrm{rCBV}$ values in the globus pallidus as the result of loss of tonic serotonergic vasoconstrictive effects to globus pallidal arterial vessels with resulting relative vasodilation producing increased blood vessel volume. In the same study, Reneman and colleagues also conducted diffusion weighted imaging to assess for differences in the apparent diffusion coefficient (ADC) of water. This technique can be used to detect changes in the free movement of water and can indirectly assay loss of structural integrity, for example with regard to fiber bundles (reviewed in Parker 2004). In this analysis, the globus pallidus of MDMA users were also the only brain region affected, with increased ADC in the MDMA cohort. Reneman et al. (2001e) speculated that the altered ADC values might be the result of loss of serotonergic axons within the globus pallidus.

Summary Overall, the Chang et al. (2000) study of baseline rCBF values in MDMA users is not supportive of chronically altered vascular diameter due to loss of serotonergic innervation. However, the presence of reduced blood flow at least 2-3 weeks post-MDMA administration has implications for the minimum abstinence period needed in studies directly examining blood flow or relying on methods dependent on neurovascular coupling, such as the functional magnetic resonance imaging (fMRI) blood oxygen level dependent (BOLD) technique. The study of Reneman et al. (2001e) is consistent with a subchronic vasodilatory state in the globus pallidus, but not in other brain regions.

\section{Brain volume}

MDMA can potentially chronically influence brain gray matter integrity through several mechanisms. These include: (1) direct and indirect neuronal or glial effects (2) changes in 5-HT coupled neurotrophic factors such as brain derived nerve growth factor (BDNF) (Duman et al. 2000) and S-100 beta (Azmitia 2002), and (3) acute or chronic vascular effects (Reneman et al. 2000b). With regard to direct and indirect neuronal effects, direct toxicity of MDMA to neuronal cell bodies has not been a prominent 
feature of basic research reports of MDMA administration. As discussed in Schmued (2003), some early reports of MDMA toxicity suggested that MDMA exposure produced scattered neuronal necrosis in rodent neocortex. Ricaurte et al. (1988) reported damaged serotonergic neurons in MDMA-exposed primates but serotonergic cell soma were unaffected in rats (O'Hearn et al. 1988). A single report found that MDMA administration to rats produced hyperthermia-dependent neuronal degeneration in multiple brain regions with the greatest numbers of degenerating neurons present in insular cortex and ventral thalamus (Schmued 2003). MDMA administration has been reported to cause glial activation in rats under some experimental paradigms (Aguirre et al. 1999) but not others (Pubill et al. 2003).

To examine gray matter integrity in MDMA users, Cowan et al. (2003) employed voxel-based morphometry (VBM), an emerging largely automated method for neuroanatomical analysis (Ashburner and Friston 2000), to compare regional brain gray matter concentration in MDMA polydrug users $(n=31)$ and controls $(n=29)$. Drug use histories were collected as ranges of lifetime use episodes, so that mean use levels were not provided. MDMA users had taken MDMA at least five times: eight had used MDMA between five and 10 times; 15 had used MDMA between 11 and 39 times; and eight MDMA users reported 40 or more MDMA exposures. MDMA users had been abstinent from MDMA for at least 3 weeks, and had significantly higher levels of polydrug exposure than the control group. Urine drug screens were negative for all subjects at study enrollment. Overall, MDMA users had multiple areas of reduced gray matter concentration in brainstem, cerebellum, and mostly left-sided neocortex that did not appear to be fully accounted for by other drug exposure. Prominently affected regions of neocortex included left Brodmann Areas (BA) 45 and 21, as well as bilateral BA 18.

While there have been no additional reports using the VBM method in MDMA users, there has not been strong evidence from other methodologies to suggest reduced brain gray matter volume or concentration in MDMAexposed humans in regions overlapping with those detected using VBM. A single study of resting metabolism in a large cohort of MDMA users (reviewed below) revealed significantly lower metabolic rate in bilateral caudate and putamen and left amygdala (Buchert et al. 2001; Obrocki et al. 2002) but these regions did not show gray matter alterations in the Cowan et al. (2003) VBM study. Chang et al. (2000), in their previously mentioned CBF study, detected a negative correlation between duration of MDMA use and global brain volume, but overall found no differences between MDMA users and controls in global brain volume, global cerebrospinal fluid (CSF), and percent CSF. Magnetic resonance spectroscopy (MRS) studies of
$N$-acetylaspartate (NAA) (reviewed below) used voxel placements that did not overlap exactly with the affected brain regions detected by VBM. So, it remains unclear whether MRS studies targeting those regions might produce evidence of lower NAA concentration, a potential spectroscopic correlate of neuronal volume loss (Gujar et al. 2005).

Summary A single VBM study found reduced gray matter density in multiple brain regions. These findings have not been replicated. Complementary neuroimaging methods do not show evidence for altered brain gray matter in regions overlapping with those showing reduced gray matter density.

\section{Brain metabolites: myoinositol and N-acetylaspartate}

As indirect indicators of structural brain components, two brain metabolites NAA and myoinositol (MI) have been systematically investigated in MDMA users (Table 2).

If NAA is considered as a specific neuronal marker, NAA levels might be predicted to covary with neuron number or size (Gujar et al. 2005). Under this scenario, MDMA toxicity might lead to reduction in NAA through direct neuronal loss, reductions in neuronal volume due to loss of 5-HT-coupled neurotrophic factors, or perhaps due to direct loss of NAA in degenerated 5-HT axons (Chang et al. 1999; Cowan et al. 2003). Furthermore, while NAA is often cited as a neuronal specific marker (Guimaraes et al. 1995), it is mitochondrially synthesized (Patel and Clark 1979; Bates et al. 1996) and may be present in adult glia as well (Sager et al. 1999; Bhakoo and Pearce 2000). Decreased NAA may serve as a reversible marker of neuronal injury (e.g., Kalra et al. 1998; de Stefano et al. 1995). Levels of NAA have been demonstrated to correlate with overall neuropsychological performance, suggesting that NAA has a global role in neuronal function (Jung et al. 1999). Like MI levels, NAA levels in MDMA users could theoretically be altered due to direct MDMA actions, or other glial, neuronal, or metabolic effects.

If MI is considered as a specific glial marker (e.g., Bitsch et al. 1999; Rumpel et al. 2003), then MI levels could potentially assay glial activation in response to MDMAinduced serotonergic axon degeneration (Chang et al. 1999). However, glial activation in terms of increased glial number, size, or metabolism after MDMA exposure is not likely solely the result of glial response to axon degeneration. MI is an important compound in cell membranes and second messenger cascades and has been implicated in psychiatric disorders such as bipolar disorder (Stoll et al. 2000). Increased MI and choline due to glial proliferation have been shown in demyelinating disorders (Bitsch et al. 1999), and may serve as osmolytes in glial cell volume regulation (Ross et al. 1996). As such, MDMA might 
Table 2 Magnetic resonance spectroscopy studies in MDMA users

\begin{tabular}{|c|c|c|c|c|c|c|c|}
\hline Metabolite & Result & Region surveyed & $\begin{array}{l}\text { MDMA use } \\
\text { mean (SD) }\end{array}$ & $\begin{array}{l}\text { MDMA } \\
\text { abstinence } \\
\text { mean (SD) }\end{array}$ & $\begin{array}{l}\text { Sample } \\
\text { size }\end{array}$ & Comment & Reference \\
\hline NAA MI & $\begin{array}{l}\text { Increased MI in } \\
\text { right parietal } \\
\text { white matter in } \\
\text { MDMA users }\end{array}$ & $\begin{array}{l}\text { Midfrontal gray matter, } \\
\text { midoccipital gray } \\
\text { matter, right parietal } \\
\text { white matter }\end{array}$ & $\begin{array}{l}75{\text { (n.g. })^{\mathrm{a}}} \\
\text { occasions }\end{array}$ & $\begin{array}{l}122(\text { n.g.) } \\
\text { days }\end{array}$ & $\begin{array}{l}21 \text { MDMA; } \\
37 \text { control }\end{array}$ & $1.5 \mathrm{~T}$ MRS & $\begin{array}{l}\text { Chang } \\
\text { et al. } \\
1999\end{array}$ \\
\hline NAA & $\begin{array}{l}\text { No NAA differences } \\
\text { in MDMA users }\end{array}$ & $\begin{array}{l}\text { Bilateral } \\
\text { hippocampus }\end{array}$ & n.g. (n.g.) & n.g. (n.g.) & $\begin{array}{l}5 \text { MDMA; } \\
5 \text { control }\end{array}$ & $1.5 \mathrm{~T}$ MRSI & $\begin{array}{l}\text { Obergriesser } \\
\text { et al. } 2001\end{array}$ \\
\hline NAA & $\begin{array}{l}\text { Impaired delayed } \\
\text { recall in MDMA } \\
\text { users correlated } \\
\text { with lower NAA }\end{array}$ & $\begin{array}{l}\text { Prefrontal cortex, } \\
\text { occipital gray matter, } \\
\text { temporo-parietal } \\
\text { white matter }\end{array}$ & $\begin{array}{l}902.0 \\
(801.2) \\
\text { tablets }\end{array}$ & $\begin{array}{l}216(337.7) \\
\text { days }\end{array}$ & $\begin{array}{l}8 \text { MDMA; } \\
7 \text { control }\end{array}$ & $1.5 \mathrm{~T}$ MRS & $\begin{array}{l}\text { Reneman } \\
\text { et al. } \\
\text { 2001d }\end{array}$ \\
\hline NAA MI & $\begin{array}{l}\text { Reduced NAA in } \\
\text { midfrontal gray } \\
\text { matter in MDMA } \\
\text { users }\end{array}$ & $\begin{array}{l}\text { Midfrontal gray matter, } \\
\text { midoccipital gray } \\
\text { matter, right parietal } \\
\text { white matter }\end{array}$ & $\begin{array}{l}723 \text { (n.g.) } \\
\text { tablets }\end{array}$ & $\begin{array}{l}84 \text { (n.g.) } \\
\text { days }\end{array}$ & $\begin{array}{l}15 \text { MDMA; } \\
12 \text { control }\end{array}$ & $1.5 \mathrm{~T}$ MRS & $\begin{array}{l}\text { Reneman } \\
\text { et al. } \\
2002 d\end{array}$ \\
\hline NAA & $\begin{array}{l}\text { No NAA differences } \\
\text { in MDMA users }\end{array}$ & $\begin{array}{l}\text { Left hippocampus, } \\
\text { midfrontal gray } \\
\text { matter, midoccipital } \\
\text { gray matter }\end{array}$ & $\begin{array}{l}324.5 \\
(416.4) \\
\text { tablets }\end{array}$ & $\begin{array}{l}47.3(52.8) \\
\text { days }\end{array}$ & $\begin{array}{l}13 \text { MDMA; } \\
13 \text { control }\end{array}$ & $\begin{array}{l}\text { 1.5 T MRS } \\
\text { MDMA } \\
\text { and controls } \\
\text { abstained } \\
\text { from cannabis } \\
\text { for } 1 \text { day }\end{array}$ & $\begin{array}{l}\text { Daumann } \\
\text { et al. } \\
2004 b\end{array}$ \\
\hline
\end{tabular}

$N A A N$-acetylaspartate, $M I$ myoinositol, $n . g$. not given

${ }^{\mathrm{a}}$ MDMA use given as occasions of use; number of tablets not provided

produce elevated MI in MDMA users due to glial response to axon degeneration or direct drug (or metabolite) effects on glial function or metabolic activity. Therefore, altered MI does not appear to be a specific marker of MDMAinduced neurotoxicity but may serve other functions as a marker of MDMA exposure.

Findings from the current literature do not suggest a consistent pattern of regional brain metabolite changes in MDMA users. Chang et al. (1999), in a $1.5 \mathrm{~T}$ (Tesla) proton MRS study examined NAA and MI in midfrontal gray matter, midoccipital gray matter, and right parietal white matter in 21 MDMA users and 37 control subjects. The MDMA-using group had used MDMA an average of 75 times with a range of $6-1,500$ times. The estimated mean total usage of MDMA was $13.1 \mathrm{~g}$ with a range of $0.5-263 \mathrm{~g}$. MDMA users had elevated parietal white matter MI/creatine (Cr) and MI in occipital cortex gray matter was positively correlated with extent of prior MDMA use. NAA to $\mathrm{Cr}$ ratios did not differ from the control group in either tested region.

Reneman et al. (2001d) reported impaired delayed memory recall performance in MDMA users that was correlated with reduced NAA/Cr in prefrontal cortex, but not with NAA/Cr in temporo-parietal gray white matter or midoccipital gray matter.
Employing voxel placements overlapping with those used by Chang et al. (1999), Reneman et al. (2002d) used proton MRS at $1.5 \mathrm{~T}$ to examine midfrontal gray, midocciptal gray, and right parietal white matter NAA and MI in MDMA users and polydrug using controls. This study found reduced NAA/ $\mathrm{Cr}$ and NAA/choline (Cho) ratios in the frontal cortex of MDMA users but no midfrontal MI/Cr differences between the two groups. There were no differences in NAA/Cr, NAA/ Cho, or $\mathrm{MI} / \mathrm{Cr}$ in midoccipital cortex or in parietal white matter. Reneman et al. (2002d) further demonstrated a significant inverse correlation between MDMA exposure level and midfrontal NAA/Cho and NAA/Cr.

In a study using proton magnetic resonance spectroscopic imaging (MRSI) at $1.5 \mathrm{~T}$ (Obergriesser et al. 2001), a small sample of five MDMA users did not differ from five agematched nondrug using controls on measures of bilateral hippocampal $\mathrm{NAA} /(\mathrm{Cr}+\mathrm{Cho})$ ratios. MDMA users had used a minimum of 120 doses of MDMA with a range of (120-350 doses). MDMA users showed no impairment on neuropsychological assays including working memory. Although urine drug testing was not obtained, subjects reported MDMA abstinence periods ranging from 3 weeks to 4 months.

More recently, Daumann et al. (2004b) used proton MRS to investigate midline neocortical and left hippocampal 
$\mathrm{NAA}$ at $1.5 \mathrm{~T}$ as $\mathrm{NAA} / \mathrm{Cr}$ ratio in a group of $13 \mathrm{MDMA}$ users and 13 controls. MDMA users had used a lifetime average of $324.54 \pm 416.43$ MDMA tablets and had been abstinent from MDMA for $47.38 \pm 52.81$ days. MDMA users reported a minimum MDMA abstinence period of 7 days and MDMA users and controls were asked to stop using cannabis the day before the study. Subjects were excluded if their urine drug screens were positive for drugs other than cannabis on the study day. All subjects participated in immediate and delayed memory tests before scanning. In the memory performance comparisons, MDMA users showed significantly reduced immediate recall when compared to the control group. In contrast, there were no detectable differences in $\mathrm{NAA} / \mathrm{Cr}$ ratios in midline frontal or occipital cortex. Hippocampal (left) $\mathrm{NAA} / \mathrm{Cr}$ showed a nonsignificant trend $(p=0.07)$ for lower $\mathrm{NAA} / \mathrm{Cr}$ in the MDMA user group.

Summary In summary, spectroscopic studies in human MDMA users have revealed no consistent findings in relation to MI and NAA. A single study (Chang et al. 1999) found increased parietal white matter MI and a positive correlation between degree of prior MDMA exposure and occipital MI. In contrast, a similarly designed study by Reneman et al. (2002d) found no association between MDMA use and cortical MI. Conversely, while Chang et al. (1999) found no association between MDMA and NAA in any region studied, Reneman et al. (2002d) reported reduced frontal NAA and a correlation between impaired memory performance and reduced NAA (Reneman et al. 2001d). Other investigators did not report reduced cortical (Daumann et al. 2004b) or hippocampal (Obergriesser et al. 2001; Daumann et al. 2004b) NAA in MDMA users. As discussed in Reneman et al. 2002d and Daumann et al. 2004b, differences in MDMA exposure may have contributed to the observed results for NAA with the greatest MDMA use in the Reneman et al. 2001d and 2002d studies, while MDMA use was lower in the Daumann et al. (2004b) report, and lower still in the cohort studied by Chang et al. (1999).

\section{Imaging brain function}

Functional neuroimaging studies in MDMA users have been conducted using PET and fMRI (Table 3). Studies to date have examined resting glucose metabolism and evoked brain activation during attentional, working memory, and episodic memory paradigms.

\section{Resting metabolism}

In preliminary (Obrocki et al. 1999) and follow-up reports (Buchert et al. 2001; Obrocki et al. 2002), Obrocki and colleagues used 2-[18F]-fluoro-2-deoxy-D-glucose (FDG) PET to examine resting metabolism in MDMA users. The comparison group was composed of oncology patients (without known brain metastases) who underwent FDG PET for diagnostic reasons. In the preliminary report, analysis was restricted to bilateral brain regions including the cingulate, BA 10 and 11, putamen, caudate, amygdala, and hippocampus. While several trends for reduced metabolism in the MDMA user group $(N=7)$ were observed, only the left hippocampus showed significant reductions in metabolism. In two later reports (which appear to be slightly different reports on the same study cohort) (Buchert et al. 2001; Obrocki et al. 2002), 93 MDMA users were compared to 27 oncology controls. The originally reported finding (Obrocki et al. 1999) of reduced left hippocampal metabolism was no longer significant, but MDMA users showed reduced metabolism in bilateral caudate/putamen and in the left amygdala. Additional analyses revealed no association between cumulative MDMA dose and FDG uptake. Scattered brain regions showed an association between the duration of MDMA abstinence and FDG uptake and some regions also showed an association between age at first MDMA use and FDG uptake (Buchert et al. 2001; Obrocki et al. 2002).

\section{Attention}

Gamma et al. (2001) used $\left[{ }^{15} \mathrm{H}_{2} \mathrm{O}\right]$ PET during performance of a visual $\mathrm{A}-\mathrm{X}$ version of a continuous performance task (CPT) to assay rCBF in MDMA users and control subjects. Subjects were also assayed for mood scores to determine whether MDMA users had increased levels of depression. Across both groups (i.e., MDMA and control combined), the CPT increased $\mathrm{rCBF}$ in right superior frontal lobe, left precentral cortex, right post central cortex, and right medial occipital lobe. Regions showing decreased rCBF across both groups included bilateral medial and superior temporal lobe as well as right precuneus. MDMA users had more polydrug exposure than control subjects, were slightly younger and less educated, and showed greater evidence of depression on the mood assessments. However, there were no differences in rCBF between MDMA users and the control group during task performance. Additionally, there were no associations between lifetime drug exposure and rCBF for any drug tested [MDMA, cannabis, amphetamine, cocaine, lysergic acid diethylamide (LSD), and magic mushrooms]. There were also no group differences in CPT performance.

\section{Working memory}

Daumann et al. (2003b) used fMRI at $1.5 \mathrm{~T}$ to examine working memory performance in MDMA users and 


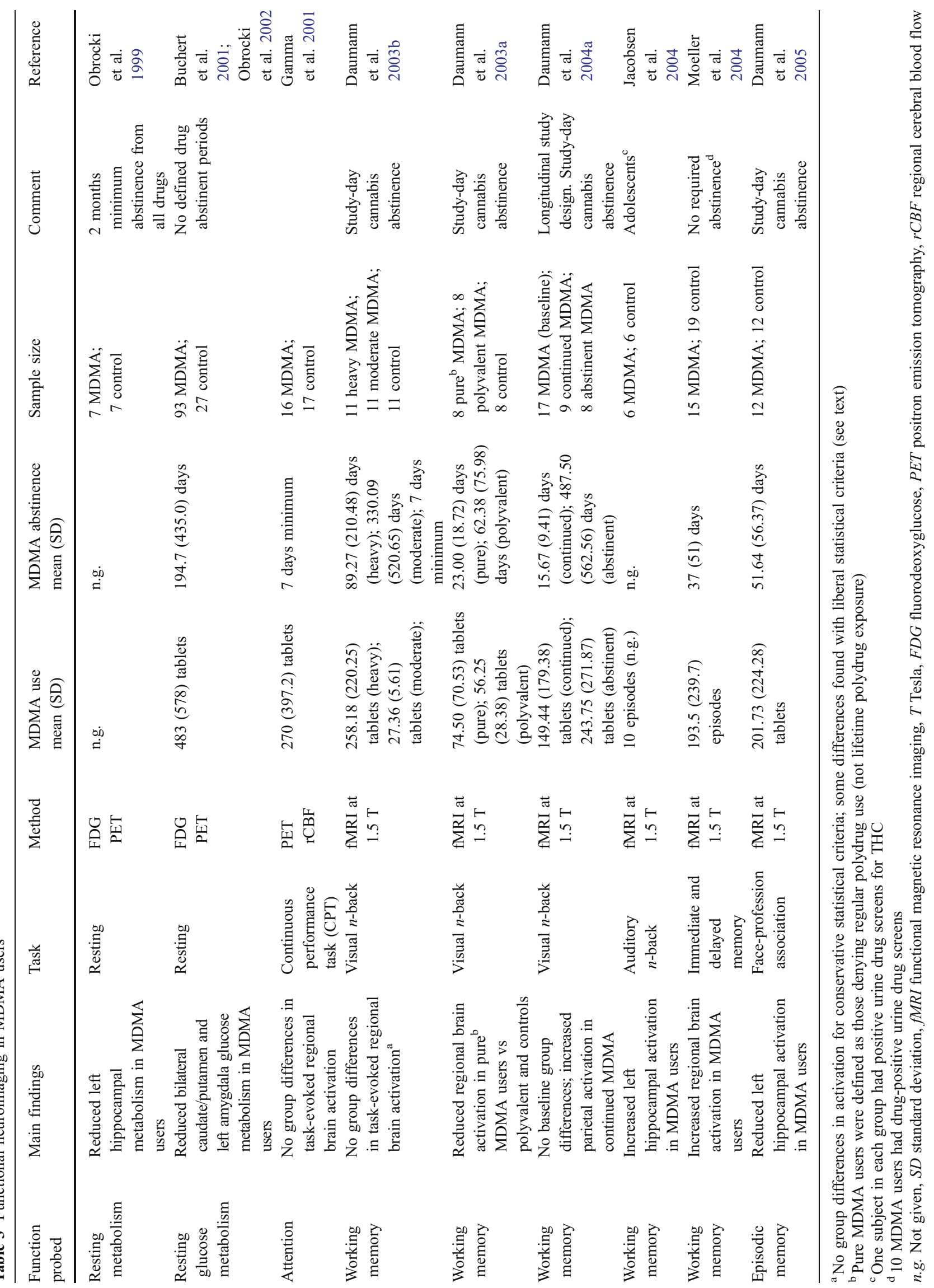


controls. Using a median split statistical procedure, MDMA users were divided into 11 heavy users (lifetime MDMA tablets 80 or more) and 11 moderate MDMA users (less than 80 tablets lifetime). Both groups of users had exposure to other drugs including cannabis and amphetamines. MDMA users were asked to abstain from all drug use except cannabis for 7 days before the fMRI scans and were allowed to use cannabis up to the study day. All subjects had negative urine drug screens for drugs of abuse other than cannabis on the fMRI study day. The working memory task employed during fMRI scanning consisted of an $n$-back task at three levels of difficulty (0-back, 1-back, and 2-back). In this task, subjects were shown a visual presentation of a group of letters and responded when a predefined target letter was presented. For the 0-back condition, subjects responded when the target letter first appeared. For the 1-back condition, subjects responded when the same letter appeared twice in a row. For the 2-back condition, subjects responded when a letter matched one delivered two letters earlier. Of these tasks, the 2-back condition was considered the most challenging to working memory because subjects had to remember the previously presented letters for the longest period of time. In regard to task performance during fMRI scanning, reaction time and error rate were significantly increased in association with increasing levels of task difficulty across all groups of subjects. However, moderate and heavy MDMA users did not differ from each other or controls when compared on reaction time and accuracy for all three $n$-back tasks. Across all groups, the $n$-back tasks produced regional BOLD signal changes in prefrontal, parietal, occipital, and cingulate cortices. The fMRI results were compared between groups at 3-levels of statistical significance: $p<0.05$ corrected for multiple independent comparisons, $p<0.01$ (uncorrected), and $p<0.001$ (uncorrected). For the 0 -back task, there were no group differences at any level of significance. For the 1-back condition, at the $p<0.01$ threshold, both groups of MDMA users had greater activations in right parietal cortex than control subjects, but this difference persisted only for the moderate user vs control comparison at the $p<0.001$ cutoff.

In a separate report, Daumann et al. (2003a) used the same methods as described above (Daumann et al. 2003b) to compare eight "pure" MDMA users to eight MDMA polydrug users and eight drug naïve controls. "Pure" MDMA users were defined as those denying regular use of substances other than MDMA (regular substance use was defined as drug use at least once per month for over 6 months in the past 2 years). Therefore, this definition of "pure" did not completely exclude other substances or heavy use of other drugs before the 2-year cutoff period. Seven subjects had participated in the prior study (Daumann et al. 2003b). A single statistical threshold of $p<0.001$ was employed to compare task-induced regional brain activation by group at three levels of the $n$-back task. The pure MDMA user group had longer duration of regular use (34 \pm 26 months) vs $18 \pm 14$ months for the MDMA polydrug users, and a later mean age of onset of MDMA use (22.8 3.7 years old) vs $19.0 \pm 1.9$ years old for the MDMA polydrug user group. With regard to performance during the fMRI task, there were no differences across groups in reaction time or accuracy. The fMRI analysis revealed no group differences during performance of the 0-back task. During the 1-back and 2-back tasks, several brain regions showed group differences in activation but the findings did not strongly overlap or show a clear pattern in the two tasks. Of the comparisons performed, the contrast between brain activation in pure MDMA users vs controls seems most pertinent to the issue of MDMA effects, per se and will be discussed in this review. Pure MDMA users showed areas of greater activation relative to controls only in the right superior parietal lobule in the 1-back task and no areas of greater activation relative to controls in the 2-back task. In contrast, pure MDMA users showed areas of lower activation relative to controls in multiple regions in the 1-back task (left posterior cingulate cortex, bilateral inferior temporal gyri, and bilateral angular gyri) while in the 2-back task, pure MDMA users had lower activation relative to controls only in left striate cortex.

An additional study by Daumann et al. (2004a) used the same working memory paradigm and methods described above (Daumann et al. 2003b) to conduct a prospective study of MDMA users at baseline and after an approximately 18-month follow-up period. At the 18-month follow-up, users were divided into a group with no interim MDMA or amphetamine use and users who had continued MDMA/amphetamine use. For continuing users, the mean number of MDMA tablets used was $35.6 \pm 22.8$ and the average amphetamine ingestion was $28.5 \pm 47.6 \mathrm{~g}$. There were no differences in task performance measures of reaction time and correct response between the baseline and subsequent (18 month) assessments for either group. Interim-abstinent subjects showed no group BOLD activation differences between the baseline and follow-up scans while subjects who continued using MDMA or amphetamines showed increased task-evoked BOLD signal in parietal cortex relative to their initial baseline assessments. Notably, increased activation in the continuing drug users was positively correlated with the lifetime average MDMA dosage, but not with the degree of exposure to other drugs.

These investigators (Daumann et al. 2004a) summarized the general trend among their series of experiments as consistent with increased parietal activation in MDMA users associated, in particular, with the one-night dosage of MDMA. Citing similar findings in individuals infected with the human immunodeficiency virus (HIV) (Chang et al. 
2001; Ernst et al. 2002), Daumann and colleagues speculated that the employed fMRI BOLD method might show greater sensitivity to drug-induced toxicity than the cognitive performance measures.

Using a visually-based working memory task that probed the function of brain regions only partially overlapping with those investigated by Daumann et al. (2003a,b, 2004a), Moeller et al. (2004) used fMRI at $1.5 \mathrm{~T}$ to compare regional brain activation during a working memory task in MDMA users and controls. The working memory task consisted of an immediate and delayed visual memory task in which subjects responded to a visually displayed target stimulus. In the delayed memory task (DMT), distracter stimuli were interposed between the target and probe stimuli. The length of delay and the number of target stimuli thus influenced the duration of working memory and the degree of working memory load, respectively. BOLD activation for the overall task was calculated as regions activated by the DMT relative to the IMT (as a baseline). MDMA users in this study reported a history of polydrug and alcohol use whereas control subjects reported only prior alcohol use. Subjects did not have a fixed abstinence period from drugs or alcohol, and 10 of the 15 MDMA users had positive urine drug screens for tetrahydrocannabinol (THC), cocaine, or amphetamine/MDMA. None of the control subjects had positive urine drug screens.

Across both MDMA user and control groups, the task activated left superior frontal gyrus, right middle frontal gyrus, left superior parietal lobule, and right precuneus and insular regions. In the comparison of MDMA users vs controls, MDMA users had multiple regions of greater BOLD activation relative to controls, but there were no regions showing greater activation in controls than in MDMA users. In the main analysis, regions activating more strongly in MDMA users included: (1) a prefrontal cluster comprised of left medial and superior frontal gyrii (confluent with right medial and superior frontal gyrii), bilateral regions of the anterior cingulate gyrus, and right middle frontal gyrus; (2) a left-localized cluster consisting of thalamus, caudate/putamen, parahippocampal gyrus, hippocampal gyrus, and insula; and (3) a right-localized cluster in thalamus, lentiform nucleus, putamen, parahippocampal gyrus, hippocampus, and insula. With the exception of cannabis, the pattern of increased activation in the MDMA users was similar when the data was controlled for other drug use. When controlled for prior cannabis use, the prefrontal cluster was no longer significantly different between MDMA users and controls. An analysis of the subgroup of five MDMA users having negative urine drug screens showed increased activation in brain regions overlapping those of the main analysis by $6-36 \%$. A within subjects analysis of the MDMA users revealed no associations between the extent of MDMA use or time since last MDMA use and regional brain activation (Moeller et al. 2004).
In a unique study, where the subjects were well-matched adolescents having minimal histories of polydrug exposure, Jacobsen et al. (2004) examined hippocampal activation during a verbal working memory task using fMRI at $1.5 \mathrm{~T}$. The participants in the study were a group of adolescents enrolled in a study of tobacco use and were daily tobacco smokers. A subgroup of six adolescents who had used MDMA was compared to six well-matched controls who reported no prior exposure to MDMA. Subjects in the MDMA cohort had used MDMA between 1-25 times, with a mean exposure of 10 episodes. Last use of MDMA had occurred between 1 and 12 months before the study. Using somewhat different tasks than those employed by Daumann et al. (2005), Jacobsen and colleagues examined selective, sustained, and divided attention (outside the scanner) as well as verbal working memory during $1.5 \mathrm{~T}$ fMRI in a small cohort of adolescent MDMA users. With regard to the attention tasks, MDMA users displayed accuracy comparable to that of control subjects. However, MDMA users showed significant increases in reaction times relative to controls across selective, divided, and sustained attention tasks. The hippocampus was chosen to examine regional brain activation during auditory $n$-back task performance at three levels of working memory load and two levels of selective attention load (binaural and dichotic stimulus presentation). In the control group, the working memory task showed decreased hippocampal activation at the highest working memory load. In contrast, the MDMA group showed decreased hippocampal activation during the less demanding tasks and showed a lesser reduction during the most difficult task. A subset of participants (including all MDMA users and four controls) also underwent a three-back task that was used for within group correlations of MDMA use variables and fMRI signal. When the lifetime episodes of MDMA use, age at onset of MDMA use, and time since last MDMA dose were compared to hippocampal BOLD signal, only the time from the last MDMA exposure showed a correlation with regional brain activation. Increased duration of MDMA abstinence was associated with a greater degree of decreased hippocampal BOLD signal across multiple levels of task difficulty and significantly so for the most difficult task. That is to say, with increased duration of MDMA abstinence, hippocampal activation in the MDMA user group more closely approached the pattern seen in controls, with increasingly negative BOLD signal change (deactivation) with increased task difficulty. Jacobsen et al. (2004) speculated that loss of serotonergic innervation to the hippocampus may have been responsible for the observed effects.

\section{Episodic memory}

Daumann et al. (2005) used BOLD fMRI at 1.5 T during performance of a face-profession encoding and retrieval 
task to compare episodic memory retrieval in MDMA users and controls. The task consisted of a learning period in which subjects were asked to encode face-profession associations in one of two profession categories (artist or academic). In the recall phase, subjects were asked to match previously encoded faces with professions relative to a neutral control task. Pilot data had revealed that only the recall phase of the paradigm produced hippocampal activation so the authors reported only on data obtained during the recall phase. The study enrolled 12 MDMA users and 12 controls. MDMA users had greater daily cannabis consumption than did control subjects and 6 of the 12 MDMA users (but no control subjects) reported amphetamine use. MDMA users were abstinent from MDMA and other drugs for at least 7 days with both MDMA users and controls abstinent from cannabis for at least the day before the study. Study-day urine screens were positive for THC in 6 of 12 MDMA users and 4 of 12 control subjects. MDMA users did not differ from the control group with regard to recall accuracy during performance of the face-profession association task. However, a comparison of hippocampal BOLD fMRI signal during recall revealed reduced left hippocampal activation in the MDMA users. Amphetamine use and pattern of MDMA use did not correlate with task performance of hippocampal activation in the MDMA users. This apparent disassociation between performance and regional brain activation led Daumann et al. (2005) to speculate that regional brain activation as assayed by fMRI might have a greater sensitivity to detect early brain dysfunction than the corresponding cognitive task. The finding by Daumann et al. (2005) of reduced hippocampal activation is in contrast with that of Jacobsen et al. (2004) who found greater left hippocampal activation in adolescent MDMA users. However, the tasks employed by Jacobsen et al. (2004) was primarily a verbal working memory task in contrast to the episodic memory paradigm used by Daumann et al. (2005).

Summary At present, it is not possible to directly compare the findings from current functional neuroimaging studies in MDMA users across different research groups. Given the variability in task design, polydrug exposure differences, the unknown effect of different abstinence periods from MDMA, polydrugs, and cannabis, and differences in data analysis, the lack of replication of findings is not surprising. As discussed in Moeller et al. (2004), MDMA might influence regional brain activation via mechanisms such as altered serotonergic vascular innervation or altered neural efficiency. MDMA-induced alterations in local inhibitory processing have also been considered as potential etiologies for altered BOLD signal in hippocampus (Jacobsen et al. 2004).

\section{Discussion}

Rodent and nonhuman primate models of MDMA toxicity have been criticized from the standpoint of drug administration route, dosage size, and dosing interval. A particular focus of controversy has resided in the utility of species scaling models and whether the route of administration and dosages of MDMA administered to experimental animals have relevance to human MDMA users. While these are important theoretical criticisms of the existing literature, an alternative method for examining the relevance of the experimental animal data is to examine the predictive utility of this information in the context of data from human MDMA users.

In this regard, published human neuroimaging studies to date suggest that MDMA users have differences in regional brain structure to some degree consistent with those predicted by findings in animal models. Among existing reports, however, only nuclear imaging studies demonstrating reduced 5-HTT-ligand binding have been replicated across laboratories and with multiple methodologies. There have been no replications, and in some cases conflicting reports, among other imaging methods. Strikingly, there is little overlap among findings from differing experimental approaches that might be expected to provide complementary results.

Several areas for improved experimental design derive from the reviewed data. These can be grouped into the general categories of increased sample homogeneity, longer abstinence periods, within-group designs, longitudinal study designs, test-retest measures, 5-HT-specific study designs, and multimodal study designs. Age, sex, hormone use, demographic matching, and genetic characterization will be increasingly important to improve homogeneity. Examining drug exposure-outcome relationships within groups of MDMA users should prove useful in helping isolate MDMA-specific effects. Longitudinal designs will also be critical in examining cumulative effects of MDMA exposure and in accounting for the effects of preexisting brain differences. MDMAabstinence periods (perhaps verified by hair sampling for MDMA; Kish 2002) on the order of several months or years seem to separate long-lasting from potentially permanent effects. Given the sizeable number of external factors potentially influencing neuroimaging outcomes, a better understanding of the stability of test-retest measures seems essential. Multimodal study designs, including those accounting for 5-HT specific effects of MDMA, are also greatly needed. Such multimodal designs might include, for example, correlated ligand binding, volumetric, functional, and spectroscopic studies to isolate affected brain regions. 
In sum, it seems clear that much more research is needed before definitive conclusions can be reached regarding MDMA effects on human brain structure and function. This review focused on the existing neuroimaging findings in the context of potential confounding variables pertinent to neuroimaging research in MDMA users. While the contribution of each factor to overall variability in MDMA studies cannot be discerned, it seems clear that experimental designs that attempt to account for pertinent confounding effects will be more likely to yield informative, replicable results.

Acknowledgements The author would like to thank Dr. Ronald Salomon and an anonymous reviewer for their thoughtful critique of this work and to acknowledge Kimberly Morton, Amy Bauernfeind, and Suzanne Avery for technical assistance. The author acknowledges NIDA funding via grants DA015137 and DA016617.

\section{References}

ABC Television Network (2004) Primetime special: Peter JenningsEcstasy rising. April 1

Aguirre N, Barrionuevo M, Ramirez MJ, Del RJ, Lasheras B (1999) Alpha-lipoic acid prevents 3,4-methylenedioxy-methamphetamine (MDMA)-induced neurotoxicity. Neuroreport 10:3675-3680

American Psychiatric Association (1994) Diagnostic and statistical manual of mental disorders, 4th edn. American Psychiatric Press, Washington, DC

Ashburner J, Friston KJ (2000) Voxel-based morphometry-the methods. Neuroimage 11:805-821

Azmitia EC (2002) Cajal's hypotheses on neurobiones and neurotropic factor match properties of microtubules and S-100 beta. Prog Brain Res 136:87-100

Bankson MG, Cunningham KA (2001) 3,4-Methylenedioxymethamphetamine (MDMA) as a unique model of serotonin receptor function and serotonin-dopamine interactions. J Pharmacol Exp Ther 297:846-852

Bates TE, Strangward M, Keelan J, Davey GP, Munro PM, Clark JB (1996) Inhibition of $\mathrm{N}$-acetylaspartate production: implications for 1H MRS studies in vivo. Neuroreport 7:1397-1400

Benmansour S, Owens WA, Cecchi M, Morilak DA, Frazer A (2002) Serotonin clearance in vivo is altered to a greater extent by antidepressant-induced downregulation of the serotonin transporter than by acute blockade of this transporter. J Neurosci 22:6766-6772

Bhakoo KK, Pearce D (2000) In vitro expression of $N$-acetyl aspartate by oligodendrocytes: implications for proton magnetic resonance spectroscopy signal in vivo. J Neurochem 74:254-262

Bitsch A, Bruhn H, Vougioukas V, Stringaris A, Lassmann H, Frahm J, Bruck W (1999) Inflammatory CNS demyelination: histopathologic correlation with in vivo quantitative proton MR spectroscopy. AJNR Am J Neuroradiol 20:1619-1627

Buchert R, Obrocki J, Thomasius R, Vaterlein O, Petersen K, Jenicke L, Bohuslavizki KH, Clausen M (2001) Long-term effects of 'ecstasy' abuse on the human brain studied by FDG PET. Nucl Med Commun 22:889-897

Buchert R, Thomasius R, Nebeling B, Petersen K, Obrocki J, Jenicke L, Wilke F, Wartberg L, Zapletalova P, Clausen M (2003) Longterm effects of "ecstasy" use on serotonin transporters of the brain investigated by PET. J Nucl Med 44:375-384
Buchert R, Thomasius R, Wilke F, Petersen K, Nebeling B, Obrocki J, Schulze O, Schmidt U, Clausen M (2004) A voxel-based PET investigation of the long-term effects of "Ecstasy" consumption on brain serotonin transporters. Am J Psychiatry 161:1181-1189

Chang L, Ernst T, Grob CS, Poland RE (1999) Cerebral (1)H MRS alterations in recreational 3, 4-methylenedioxymethamphetamine (MDMA, "ecstasy") users. J Magn Reson Imaging 10:521-526

Chang L, Grob CS, Ernst T, Itti L, Mishkin FS, Jose-Melchor R, Poland RE (2000) Effect of ecstasy [3,4-methylenedioxymethamphetamine (MDMA)] on cerebral blood flow: a co-registered SPECT and MRI study. Psychiatry Res 98:15-28

Chang L, Speck O, Miller EN, Braun J, Jovicich J, Koch C, Itti L, Ernst $T$ (2001) Neural correlates of attention and working memory deficits in HIV patients. Neurology 57:1001-1007

Check E (2004) The ups and downs of Ecstasy. Nature 429:126-128

Cohen Z, Bonvento G, Lacombe P, Hamel E (1996) Serotonin in the regulation of brain microcirculation. Prog Neurobiol 50:335-362

Cole JC, Bailey M, Sumnall HR, Wagstaff GF, King LA (2002) The content of ecstasy tablets: implications for the study of their longterm effects. Addiction 97:1531-1536

Cowan RL, Lyoo IK, Sung SM, Ahn KH, Kim MJ, Hwang J, Haga E, Vimal RL, Lukas SE, Renshaw PF (2003) Reduced cortical gray matter density in human MDMA (Ecstasy) users: a voxel-based morphometry study. Drug Alcohol Depend 72:225-235

Crittenden J (2005) Harvard doc's study: dying with ecstasy. The Boston Herald. January 7

Daumann J, Schnitker R, Weidemann J, Schnell K, Thron A, Gouzoulis-Mayfrank E (2003a) Neural correlates of working memory in pure and polyvalent ecstasy (MDMA) users. Neuroreport 14:1983-1987

Daumann J, Fimm B, Willmes K, Thron A, Gouzoulis-Mayfrank E (2003b) Cerebral activation in abstinent ecstasy (MDMA) users during a working memory task: a functional magnetic resonance imaging (fMRI) study. Brain Res Cogn Brain Res 16:479-487

Daumann J Jr, Fischermann T, Heekeren K, Thron A, GouzoulisMayfrank E (2004a) Neural mechanisms of working memory in ecstasy (MDMA) users who continue or discontinue ecstasy and amphetamine use: evidence from an 18-month longitudinal functional magnetic resonance imaging study. Biol Psychiatry $56: 349-355$

Daumann J, Fischermann T, Pilatus U, Thron A, Moeller-Hartmann W, Gouzoulis-Mayfrank E (2004b) Proton magnetic resonance spectroscopy in ecstasy (MDMA) users. Neurosci Lett 362:113-116

Daumann J, Fischermann T, Heekeren K, Henke K, Thron A, Gouzoulis-Mayfrank E (2005) Memory-related hippocampal dysfunction in poly-drug ecstasy (3,4-methylenedioxymethamphetamine) users. Psychopharmacology (Berl) 180:607611

de Almeida SP, Silva MT (2003) Ecstasy (MDMA): effects and patterns of use reported by users in Sao Paulo. Rev Bras Psiquiatr 25:11-17

de la Torre R, Farre M (2004) Neurotoxicity of MDMA (ecstasy): the limitations of scaling from animals to humans. Trends Pharmacol Sci 25:505-508

de Win MM, de Jeu RA, De BK, Habraken JB, Reneman L, Booij J, den Heeten GJ (2004) Validity of in vivo [123I]beta-CIT SPECT in detecting MDMA-induced neurotoxicity in rats. Eur Neuropsychopharmacol 14:185-189

de Stefano N, Matthews PM, Arnold DL (1995) Reversible decreases in $N$-acetylaspartate after acute brain injury. Magn Reson Med 34:721-727

Doblin R (2002) A clinical plan for MDMA (Ecstasy) in the treatment of posttraumatic stress disorder (PTSD): partnering with the FDA. J Psychoactive Drugs 34:185-194 
Duman RS, Malberg J, Nakagawa S, D'Sa C (2000) Neuronal plasticity and survival in mood disorders. Biol Psychiatry 48:732-739

Ernst T, Chang L, Jovicich J, Ames N, Arnold S (2002) Abnormal brain activation on functional MRI in cognitively asymptomatic HIV patients. Neurology 59:1343-1349

European Monitoring Centre for Drugs and Drug Addiction (2005) News Release No. 9: cocaine, amphetamines, Ecstasy, and cannabis: latest trends. November 24, LISBON

Fantegrossi WE, Woolverton WL, Kilbourn M, Sherman P, Yuan J, Hatzidimitriou G, Ricaurte GA, Woods JH, Winger G (2004) Behavioral and neurochemical consequences of long-term intravenous self-administration of MDMA and its enantiomers by rhesus monkeys. Neuropsychopharmacology 29:1270-1281

Fiorella D, Helsley S, Lorrain DS, Rabin RA, Winter JC (1995) The role of the 5-HT2A and 5-HT2C receptors in the stimulus effects of hallucinogenic drugs. III: The mechanistic basis for supersensitivity to the LSD stimulus following serotonin depletion. Psychopharmacology (Berl) 121:364-372

Frankle WG, Huang Y, Hwang DR, Talbot PS, Slifstein M, Van HR, bi-Dargham A, Laruelle M (2004) Comparative evaluation of serotonin transporter radioligands $11 \mathrm{C}-\mathrm{DASB}$ and $11 \mathrm{C}-\mathrm{McN}$ 5652 in healthy humans. J Nucl Med 45:682-694

Gamma A, Buck A, Berthold T, Vollenweider FX (2001) No difference in brain activation during cognitive performance between ecstasy (3,4-methylenedioxymethamphetamine) users and control subjects: a [H2(15)O]-positron emission tomography study. J Clin Psychopharmacol 21:66-71

Gray JA, Roth BL (2001) Paradoxical trafficking and regulation of 5HT(2A) receptors by agonists and antagonists. Brain Res Bull $56: 441-451$

Green AR (2004) MDMA: fact and fallacy, and the need to increase knowledge in both the scientific and popular press. Psychopharmacology (Berl) 173:231-233

Green AR, Mechan AO, Elliott JM, O'Shea E, Colado MI (2003) The pharmacology and clinical pharmacology of 3,4-methylenedioxymethamphetamine (MDMA, "ecstasy"). Pharmacol Rev 55:463-508

Gross SR, Barrett SP, Shestowsky JS, Pihl RO (2002) Ecstasy and drug consumption patterns: a Canadian rave population study. Can J Psychiatry 47:546-551

Guimaraes AR, Schwartz P, Prakash MR, Carr CA, Berger UV, Jenkins BG, Coyle JT, Gonzalez RG (1995) Quantitative in vivo $1 \mathrm{H}$ nuclear magnetic resonance spectroscopic imaging of neuronal loss in rat brain. Neuroscience 69:1095-1101

Gujar SK, Maheshwari S, Bjorkman-Burtscher I, Sundgren PC (2005) Magnetic resonance spectroscopy. J Neuroophthalmol $25: 217-226$

Horschitz S, Hummerich R, Schloss P (2001) Down-regulation of the rat serotonin transporter upon exposure to a selective serotonin reuptake inhibitor. Neuroreport 12:2181-2184

Hurley RA, Reneman L, Taber KH (2002) Ecstasy in the brain: a model for neuroimaging. J Neuropsychiatry Clin Neurosci 14:125-129

Irvine RJ, Keane M, Felgate P, McCann UD, Callaghan PD, White JM (2006) Plasma drug concentrations and physiological measures in 'Dance Party' participants. Neuropsychopharmacology 31 (2):424-430

Jacobsen LK, Mencl WE, Pugh KR, Skudlarski P, Krystal JH (2004) Preliminary evidence of hippocampal dysfunction in adolescent MDMA ("ecstasy") users: possible relationship to neurotoxic effects. Psychopharmacology (Berl) 173:383-390

Jung RE, Yeo RA, Chiulli SJ, Sibbitt WL Jr, Weers DC, Hart BL, Brooks WM (1999) Biochemical markers of cognition: a proton MR spectroscopy study of normal human brain. Neuroreport 10:3327-3331
Kalra S, Cashman NR, Genge A, Arnold DL (1998) Recovery of $\mathrm{N}$-acetylaspartate in corticomotor neurons of patients with ALS after riluzole therapy. Neuroreport 9:1757-1761

Kish SJ (2002) How strong is the evidence that brain serotonin neurons are damaged in human users of ecstasy? Pharmacol Biochem Behav 71:845-855

Kohn D (2004) Ecstasy research looks for benefits: advocates explore use of drug, illegal since 1985, to treat emotional wounds. Baltimore Sun. July 25

Lesch KP, Bengel D, Heils A, Sabol SZ, Greenberg BD, Petri S, Benjamin J, Muller CR, Hamer DH, Murphy DL (1996) Association of anxiety-related traits with a polymorphism in the serotonin transporter gene regulatory region. Science $274: 1527-1531$

Lieberman JA, Aghajanian GK (1999) Caveat emptor: researcher beware. Neuropsychopharmacology 21:471-473

Lyles J, Cadet JL (2003) Methylenedioxymethamphetamine (MDMA, Ecstasy) neurotoxicity: cellular and molecular mechanisms. Brain Res Brain Res Rev 42:155-168

Marsa L (2005) Ecstasy's good side: The much maligned drug may ease the anxieties of the terminally ill. LA Times. April 11

McCann UD, Ricaurte GA (2001) Caveat emptor: editors beware. Neuropsychopharmacology 24:333-336

McCann UD, Szabo Z, Scheffel U, Dannals RF, Ricaurte GA (1998) Positron emission tomographic evidence of toxic effect of MDMA ("Ecstasy") on brain serotonin neurons in human beings. Lancet 352:1433-1437

McCann UD, Szabo Z, Seckin E, Rosenblatt P, Mathews WB, Ravert HT, Dannals RF, Ricaurte GA (2005) Quantitative PET studies of the serotonin transporter in MDMA users and controls using [(11)C]McN5652 and [(11)C]DASB. Neuropsychopharmacology 30:1741-1750

McGregor IS, Clemens KJ, Van der PG, Li KM, Hunt GE, Chen F, Lawrence AJ (2003) Increased anxiety 3 months after brief exposure to MDMA ("Ecstasy") in rats: association with altered 5-HT transporter and receptor density. Neuropsychopharmacology 28:1472-1484

Miner LH, Schroeter S, Blakely RD, Sesack SR (2000) Ultrastructural localization of the serotonin transporter in superficial and deep layers of the rat prelimbic prefrontal cortex and its spatial relationship to dopamine terminals. J Comp Neurol 427: 220-234

Moeller FG, Steinberg JL, Dougherty DM, Narayana PA, Kramer LA, Renshaw PF (2004) Functional MRI study of working memory in MDMA users. Psychopharmacology (Berl) 177:185-194

Montoya AG, Sorrentino R, Lukas SE, Price BH (2002) Long-term neuropsychiatric consequences of "ecstasy" (MDMA): a review. Harv Rev Psychiatry 10:212-220

Morgan MJ (2000) Ecstasy (MDMA): a review of its possible persistent psychological effects. Psychopharmacology (Berl) 152:230-248

Morton J (2005) Ecstasy: pharmacology and neurotoxicity. Curr Opin Pharmacol 5:79-86

Moses-Kolko EL, Berga SL, Greer PJ, Smith G, Cidis MC, Drevets WC (2003) Widespread increases of cortical serotonin type 2A receptor availability after hormone therapy in euthymic postmenopausal women. Fertil Steril 80:554-559

Nair SG, Gudelsky GA (2006) 3,4-Methylenedioxymethamphetamine enhances the release of acetylcholine in the prefrontal cortex and dorsal hippocampus of the rat. Psychopharmacology (Berl) 184 (2):182-189

National Drug Intelligence Center (2005) National drug threat assessment 2005 summary report. February (2005-Q0317-005)

Newton C (2001) FDA OKs clinical testing of Ecstasy. The Washington Post. November 6

O'Hearn E, Battaglia G, de Souza EB, Kuhar MJ, Molliver ME (1988) Methylenedioxyamphetamine (MDA) and methylenedioxymeth- 
amphetamine (MDMA) cause selective ablation of serotonergic axon terminals in forebrain: immunocytochemical evidence for neurotoxicity. J Neurosci 8:2788-2803

Obergriesser T, Ende G, Braus DF, Henn FA (2001) Hippocampal 1HMRSI in ecstasy users. Eur Arch Psychiatry Clin Neurosci 251:114-116

Obrocki J, Buchert R, Vaterlein O, Thomasius R, Beyer W, Schiemann T (1999) Ecstasy-long-term effects on the human central nervous system revealed by positron emission tomography. Br J Psychiatry 175:186-188

Obrocki J, Schmoldt A, Buchert R, Andresen B, Petersen K, Thomasius R (2002) Specific neurotoxicity of chronic use of ecstasy. Toxicol Lett 127:285-297

Parker GJ (2004) Analysis of MR diffusion weighted images. Br J Radiol 77:S176-S185

Parrott AC (2001) Human psychopharmacology of Ecstasy (MDMA): a review of 15 years of empirical research. Hum Psychopharmacol 16(8):557-577

Parrott AC (2004) Is ecstasy MDMA? A review of the proportion of ecstasy tablets containing MDMA, their dosage levels, and the changing perceptions of purity. Psychopharmacology (Berl) 173:234-241

Patel TB, Clark JB (1979) Synthesis of $N$-acetyl-L-aspartate by rat brain mitochondria and its involvement in mitochondrial/cytosolic carbon transport. Biochem J 184:539-546

Pedersen W, Skrondal A (1999) Ecstasy and new patterns of drug use: a normal population study. Addiction 94:1695-1706

Pubill D, Canudas AM, Pallas M, Camins A, Camarasa J, Escubedo E (2003) Different glial response to methamphetamine- and methylenedioxymethamphetamine-induced neurotoxicity. Naunyn Schmiedebergs Arch Pharmacol 367:490-499

Reneman L, Booij J, Schmand B, van den BW, Gunning B (2000a) Memory disturbances in "Ecstasy" users are correlated with an altered brain serotonin neurotransmission. Psychopharmacology (Berl) 148:322-324

Reneman L, Habraken JB, Majoie CB, Booij J, den Heeten GJ (2000b) MDMA ("Ecstasy") and its association with cerebrovascular accidents: preliminary findings. AJNR Am J Neuroradiol 21:1001-1007

Reneman L, Booij J, De BK, Reitsma JB, de Wolff FA, Gunning WB, den Heeten GJ, van den BW (2001a) Effects of dose, sex, and long-term abstention from use on toxic effects of MDMA (ecstasy) on brain serotonin neurons. Lancet 358:1864-1869

Reneman L, Booij J, Majoie CB, van den BW, den Heeten GJ (2001b) Investigating the potential neurotoxicity of Ecstasy (MDMA): an imaging approach. Hum Psychopharmacol 16:579-588

Reneman L, Lavalaye J, Schmand B, de Wolff FA, van den BW, den Heeten GJ, Booij J (2001c) Cortical serotonin transporter density and verbal memory in individuals who stopped using 3,4methylenedioxymethamphetamine (MDMA or "ecstasy"): preliminary findings. Arch Gen Psychiatry 58:901-906

Reneman L, Majoie CB, Schmand B, van den BW, den Heeten GJ (2001d) Prefrontal $\mathrm{N}$-acetylaspartate is strongly associated with memory performance in (abstinent) ecstasy users: preliminary report. Biol Psychiatry 50:550-554

Reneman L, Majoie CB, Habraken JB, den Heeten GJ (2001e) Effects of ecstasy (MDMA) on the brain in abstinent users: initial observations with diffusion and perfusion MR imaging. Radiology 220:611-617

Reneman L, Booij J, Habraken JB, De BK, Hatzidimitriou G, den Heeten GJ, Ricaurte GA (2002a) Validity of [123I]beta-CIT SPECT in detecting MDMA-induced serotonergic neurotoxicity. Synapse 46:199-205

Reneman L, Booij J, Lavalaye J, De BK, Reitsma JB, Gunning B, den Heeten GJ, van den BW (2002b) Use of amphetamine by recreational users of ecstasy (MDMA) is associated with reduced striatal dopamine transporter densities: a [123I]beta-CIT SPECT study — preliminary report. Psychopharmacology (Berl) 159:335340

Reneman L, Endert E, De BK, Lavalaye J, Feenstra MG, de Wolff FA, Booij J (2002c) The acute and chronic effects of MDMA ("ecstasy") on cortical 5-HT2A receptors in rat and human brain. Neuropsychopharmacology 26:387-396

Reneman L, Majoie CB, Flick H, den Heeten GJ (2002d) Reduced $N$ acetylaspartate levels in the frontal cortex of 3,4-methylenedioxymethamphetamine (Ecstasy) users: preliminary results. AJNR Am J Neuroradiol 23:231-237

Reneman L, de Win MM, van den Brink W, Booij J, den Heeten GJ (2006) Neuroimaging findings with MDMA/ecstasy: technical aspects, conceptual issues and future prospects. J Psychopharmacol 20:164-175

Ricaurte GA, DeLanney LE, Irwin I, Langston JW (1988) Toxic effects of MDMA on central serotonergic neurons in the primate: importance of route and frequency of drug administration. Brain Res 446:165-168

Ricaurte GA, Yuan J, McCann UD (2000) ( \pm )3,4-Methylenedioxymethamphetamine ('Ecstasy')-induced serotonin neurotoxicity: studies in animals. Neuropsychobiology 42:5-10

Rojas R, Riascos R, Vargas D, Cuellar H, Borne J (2005) Neuroimaging in drug and substance abuse Part I: cocaine, cannabis, and ecstasy. Top Magn Reson Imaging 16:231-238

Ross BD, Danielsen ER, Bluml S (1996) Proton magnetic resonance spectroscopy: the new gold standard for diagnosis of clinical and subclinical hepatic encephalopathy? Dig Dis 14 (Suppl 1):30-39

Rumpel H, Lim WE, Chang HM, Chan LL, Ho GL, Wong MC, Tan KP (2003) Is myo-inositol a measure of glial swelling after stroke? A magnetic resonance study. J Magn Reson Imaging 17:11-19

Sager TN, Thomsen C, Valsborg JS, Laursen H, Hansen AJ (1999) Astroglia contain a specific transport mechanism for $N$-acetyl-Laspartate. J Neurochem 73:807-811

Scheffel U, Lever JR, Stathis M, Ricaurte GA (1992) Repeated administration of MDMA causes transient down-regulation of serotonin 5-HT2 receptors. Neuropharmacology 31:881-893

Schifano F, Di FL, Forza G, Minicuci N, Bricolo R (1998) MDMA ('ecstasy') consumption in the context of polydrug abuse: a report on 150 patients. Drug Alcohol Depend 52:85-90

Schmued LC (2003) Demonstration and localization of neuronal degeneration in the rat forebrain following a single exposure to MDMA. Brain Res 974:127-133

Scholey AB, Parrott AC, Buchanan T, Heffernan TM, Ling J, Rodgers $\mathrm{J}$ (2004) Increased intensity of Ecstasy and polydrug usage in the more experienced recreational Ecstasy/MDMA users: a WWW study. Addict Behav 29:743-752

Semple DM, Ebmeier KP, Glabus MF, O'Carroll RE, Johnstone EC (1999) Reduced in vivo binding to the serotonin transporter in the cerebral cortex of MDMA ('ecstasy') users. Br J Psychiatry 175:63-69

Simantov R (2004) Multiple molecular and neuropharmacological effects of MDMA (Ecstasy). Life Sci 74:803-814

Stoll AL, Renshaw PF, Yurgelun-Todd DA, Cohen BM (2000) Neuroimaging in bipolar disorder: what have we learned? Biol Psychiatry 48:505-517

Tanner-Smith EE (2006) Pharmacological content of tablets sold as "ecstasy": results from an online testing service. Drug Alcohol Depend 83(3):247-254

The Partnership for a Drug-Free America (2003) PATS study 2003teens: teen Ecstasy use leveling off after steep increase, but majority still see scan risk in experimenting with " $\mathrm{X}$ ". February 10 
Thomasius R, Petersen K, Buchert R, Andresen B, Zapletalova P, Wartberg L, Nebeling B, Schmoldt A (2003) Mood, cognition and serotonin transporter availability in current and former ecstasy (MDMA) users. Psychopharmacology (Berl) 167:85-96

Turecki G, Briere R, Dewar K, Antonetti T, Lesage AD, Seguin M, Chawky N, Vanier C, Alda M, Joober R, Benkelfat C, Rouleau GA (1999) Prediction of level of serotonin 2A receptor binding by serotonin receptor $2 \mathrm{~A}$ genetic variation in postmortem brain samples from subjects who did or did not commit suicide. Am J Psychiatry 156:1456-1458

Van Oekelen D, Luyten WH, Leysen JE (2003) 5-HT2A and 5-HT2C receptors and their atypical regulation properties. Life Sci 72:2429-2449

Varnas K, Halldin C, Hall H (2004) Autoradiographic distribution of serotonin transporters and receptor subtypes in human brain. Hum Brain Mapp 22:246-260

Verrico CD, Miller GM, Madras BK (2005) MDMA (Ecstasy) and human dopamine, norepinephrine, and serotonin transporters: implications for MDMA-induced neurotoxicity and treatment. Psychopharmacology (Berl) 1-15

Wang X, Baumann MH, Xu H, Rothman RB (2004) 3,4methylenedioxymethamphetamine (MDMA) administration to rats decreases brain tissue serotonin but not serotonin transporter protein and glial fibrillary acidic protein. Synapse $53: 240-248$

Wang X, Baumann MH, Xu H, Morales M, Rothman RB (2005) ( \pm )3,4-Methylenedioxymethamphetamine administration to rats does not decrease levels of the serotonin transporter protein or alter its distribution between endosomes and the plasma membrane. J Pharmacol Exp Ther 314:1002-1012

Yamamoto M, Suhara T, Okubo Y, Ichimiya T, Sudo Y, Inoue M, Takano A, Yasuno F, Yoshikawa K, Tanada S (2002) Age-related decline of serotonin transporters in living human brain of healthy males. Life Sci 71:751-757

Zhou FC, Tao-Cheng JH, Segu L, Patel T, Wang Y (1998) Serotonin transporters are located on the axons beyond the synaptic 